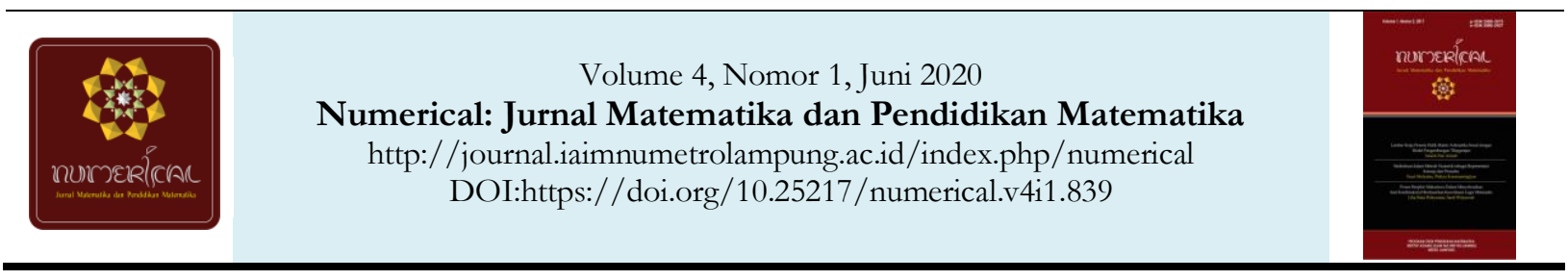

\title{
The Thinking Process of Students Using Trial and Error Strategies in Generalizing Linear Patterns
}

\author{
Yayan Eryk Setiawan
}

Pendidikan Matematika FKIP Universitas Islam Malang, Indonesia

Correspondence: yayaneryksetiawan@unisma.ac.id

\begin{tabular}{|c|c|}
\hline Article Info & Abstract \\
\hline Article History & \multirow{10}{*}{$\begin{array}{l}\text { Patterns generalization learning at the junior high school is more emphasis on } \\
\text { the generalization of linear patterns. One problem in generalizing linear patterns } \\
\text { is that students do not know the process of using trial and error strategies to } \\
\text { generalize linear patterns. For this reason, the purpose of this study was to } \\
\text { analyze the thought processes of } 2 \text { junior high school students who succeeded } \\
\text { in generalizing linear patterns using trial and error strategies. The results show } \\
\text { that there are two trial and error strategies that can be used to generalize linear } \\
\text { patterns, namely: (1) Trial and error strategy by looking at the relationship of } \\
\text { quantity consists of three steps. The first step is called relating, namely, the } \\
\text { subject connects between the first term, the term in question, and difference. } \\
\text { The second step is called searching, where the subject finds similarities by using } \\
\text { addition and subtraction operations to obtain the }{ }^{\text {th }} \text { term formula. The third } \\
\text { step is called extending; the subject expands the pattern into more general } \\
\text { structures by looking at the relationship between quantities. (2) Trial and error } \\
\text { strategy by looking at patterns that consist of three steps. The first step is called } \\
\text { relating, namely, the subject connects small positive integers by using arithmetic } \\
\text { operations to obtain the first term and the second term. The second step is } \\
\text { called searching, where the subject finds similarities by finding the formula for } \\
\text { the first, second, and third terms. The third step is called extending, where the } \\
\text { subject expands the pattern into more general structures by looking at the } \\
\text { pattern that applies to the first, second, and third terms. }\end{array}$} \\
\hline Received: 11-04-2020 & \\
\hline Revised: 04-05-2020 & \\
\hline Accepted: 10-05-2020 & \\
\hline Keywords: & \\
\hline Generalization Strategies; & \\
\hline Linear Pattern; & \\
\hline Thinking Processes; & \\
\hline Trial and Error Strategy; & \\
\hline & \\
\hline
\end{tabular}

\section{INTRODUCTION}

One of the basic competencies that must be mastered by grade eight junior high school students is to make a generalization of number patterns and configuration of objects [1] which emphasize of linear patterns material [2],[3]. Even in the NCTM document also recommended giving patterns material starting from kindergarten to senior high schools [2]. The recommendation of giving patterns material are because patterns are one of the important concepts in mathematics to be studied[4]. Patterns in mathematical contexts are defined as predictable order [2],[3]. Whereas generalization in the mathematical context is defined as the activity of expanding ideas from certain cases so that the idea applies generally [5]. Thus, the pattern generalization in this study is defined as the activity of extending the idea of the formation of terms from a linear pattern, so that it is applicable to find the value of the $\mathrm{n}^{\text {th }}$ term generally.

Patterns are classified into repeating patterns and growing patterns [2],[3]. Repeating patterns area pattern with repetitive cycles it is called repetitive units, whereas growing patternsarea pattern that involve progression from step to step [3],[6]. Furthermore, growing patterns can be either linear or quadratic patterns [3]. The linear pattern is that the first difference 
is constant[6], where the $\mathrm{n}^{\text {th }}$ term formula of a linear pattern is $U_{n}=a n+b$ with $a \neq 0$. While the quadratic pattern is a pattern that has the second difference that is constant [3],[6], where the $\mathrm{n}^{\text {th }}$ term formula of a quadratic pattern is $U_{n}=a n^{2}+b n+c$ with $a \neq 0$. This study focused on a linear pattern because the learning patterns of the junior high school level is more emphasis on the linear pattern [2].

Previous research shows that the strategies used by students in generalizing of linear patterns are dominated by the use of numerical strategies [7]. One of numerical strategy is a trial and error strategy. This trial and error strategy is a strategy of generalizing linear patterns that starts from creating a formula for a small case, then trying for the next case. If the formula does not match, then the student will change the formula until he can obtain the $\mathrm{n}^{\text {th }}$ term formula. However, students who use this trial and error strategy fail a lot, because students do not know the coefficients of linear patterns, which in turn students fail to generalize linear patterns [7]. It is can be said that failure in using the trial and error strategy is due to not knowing the steps in using the trial and error strategy to generalize the linear pattern. For the alternative solution to student failure using this trial and error strategy, this study will present the thought processes of students who have successfully used a trial and error strategy in generalizing linear patterns. So the difference of this study with previous research is if previous research shows that students fail to generalize linear patterns caused by using a trial and error strategy [7], while this study will show that students have succeeded in generalizing linear patterns using trial and error strategies.

The benefit of this research is to provide a new theory about the successful use of trial and error strategies to generalize linear patterns. Because all this time the trial and error strategy is considered to be the cause of students' failure to generalize patterns. The results of this study are useful for students who use trial and error strategies in generalizing linear patterns. The results of this study can also be used by teachers to guide their students using trial and error strategies in generalizing linear patterns.

\section{METHOD}

This research approach uses descriptive qualitative research that aims to describe the thought processes of students who use trial and error strategies in generalizing linear patterns. This research was conducted in one of the junior high schools in Lumajang district in the 2019/2020 academic year in the odd semester. From 23 grade eight students, there were 2 students who successfully used the trial and error strategy in generalizing linear patterns. Both students will be the participants of this study.

The instrument of this study is a linear pattern problem with the representation of terms using numbers (Figure 1). The reason researcher use number representations for the linear pattern is based on the results of research that students who tend to use numerical strategies in generalizing number pattern can also lead to a trial and error strategy [7]. So instruments in the form of number patterns can be used to find out the trial and error strategy in generalizing linear patterns.

The procedure of this study consisted of two stages. The first stage is determining the research participants. The results of the work of 23 eighth grade students who completed the generalization of the linear pattern (see Figure 1) were collected and classified based on the 
generalization strategy used. From the 23 students' answers, 2 students used the trial and error strategy. Furthermore, these 2 students were selected as research participants.

Consider the number pattern is below.

$$
6,10,14,18, \ldots
$$

Determine:

(a) Numbers in the $5^{\text {th }}$ to $10^{\text {th }}$ terms!

(b) The formula of the $\mathrm{n}^{\text {th }}$ term!

(c) Numbers in the $57^{\text {th }}$ term!

Figure 1. Research Instrument

The second stage is to analyze the thought processes of the 2 research participants. Analysis of the participants' thinking process uses a framework of generalization actions consisting of three categories, namely relating, searching, and extending [8]. The act of relating to this study is the act of connecting between two or more terms in a number pattern. The act of searching is an act of repetition, for example calculating ratios or searching for patterns to find of similarity. The act of extending is the act of extending a pattern into a more general structure.

This research data is qualitative, namely the results of work and interview transcripts with research participants. The results of the participants' work were analyzed to find the process of using a trial and error strategy. While the interview transcripts data from the research participants are used to validate the findings from the analysis of partisipats' work. Also, coding of interview transcripts was carried out to find terms that emerge from the partisipats' thought process in solving linear pattern problems using trial and error strategies. By analyzing the results of the work and interview transcripts of the participants, it is expected that participants' thought processes can be found that use trial and error strategies in generalizing linear patterns.

\section{RESULTS AND DISCUSSION}

From the results of the analysis of the participants' answers obtained two types of thought processes in generalizing linear patterns using trial and error strategies. The first thought process is a trial and error strategy by looking at quantity relationship. The second thought process is a trial and error strategy by looking at patterns. Each of these thinking processes is explained below.

\section{The Thinking Process of Trial and Error Strategy by Looking at Quantity Relationships}

The thought process of the trial and error strategy by looking at the quantity relationship is the process of thinking in generalizing of the linear pattern starting with the trial and error strategy and continuing by looking at the quantity relationship, so as to generalize the linear pattern. The work results of the first participant is using a trial and error strategy by looking at the quantity relationship can be seen in Figure 2 . 


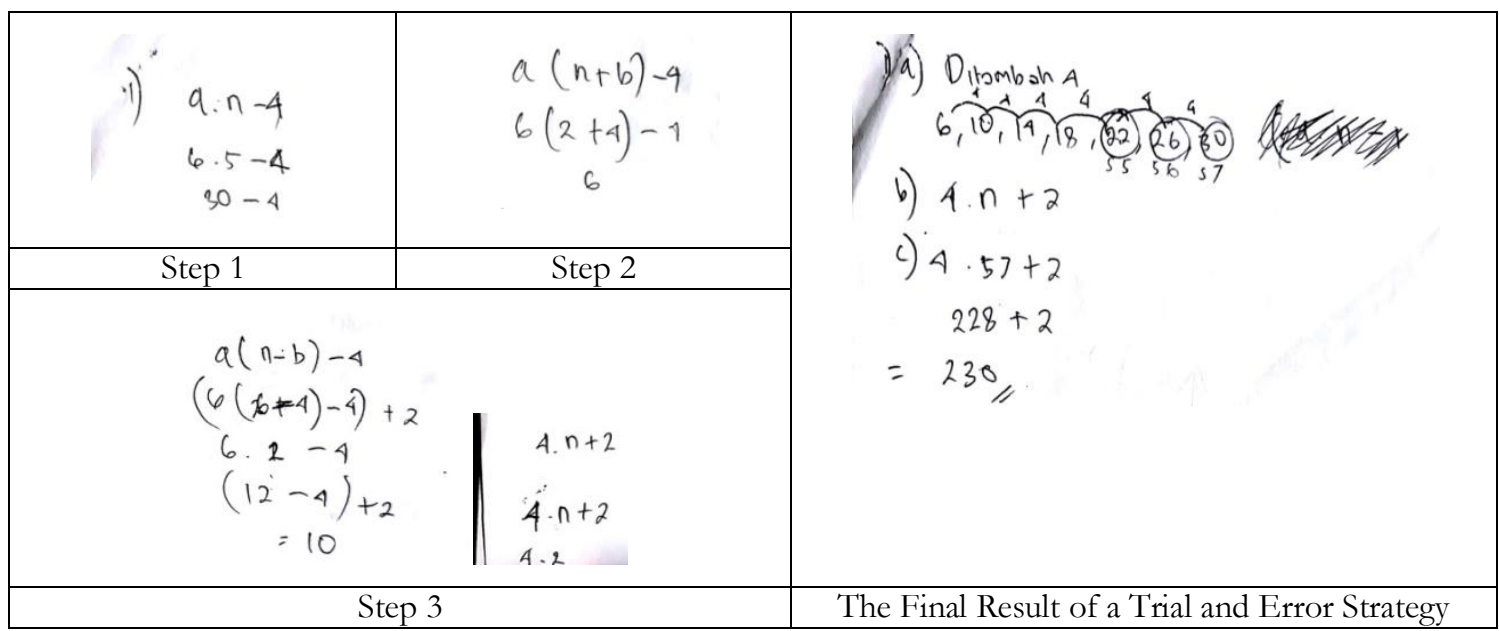

Figure 2. Work Result of the First Participant Using Trial and Error Strategy

From Figure 2 it can be seen that the participant's thought process consists of 3 steps. Furthermore, the steps of the trial and error strategy used by the first participant (P1) can be seen from the following interview results.

$\mathrm{R} \quad: \quad$ Where did you get the $5^{\text {th }}$ term?

P1 : From 18 plus 4 , so that it is obtained $18+4=22$

$\mathrm{R} \quad$ : Where did you get the formula $a_{n}-4$ ?

P1 : $\quad a$ is the first term, $n$ is the fifth term that is a term in question, and 4 is the difference.

Because the difference is negative, so I write -4 , so I wrote $a_{n}-4$.

Then I substitute $n=5$, then obtained $6.5-4=26$. Then I compared it with 22, and the results were wrong. Then I find another way.

$\mathrm{R} \quad$ : Why did you write down the formula $a(n+b)-4$ ?

P1 : Because my method was wrong, I tried adding a difference (b) to n, so I tried to find the fifth term, which is $6(5+4)-4=6(9)-4=50$ turned out wrong.

$\mathrm{R} \quad$ : Why did you write down $a(n-b)-4$ ?

P1 : Because it was wrong, so I tried to reduce it.

I take $n=6$, so $6(6-4)-4=6(2)-4=8$, turned out wrong.

$\mathrm{R}$ : How do you get the formula $4 n+2$ !

P1 : Earlier I took $n=6$, it was wrong, that is $(12-4)=8$. Because the resulting number is approaching the $2^{\text {nd }}$ term, then I try to add 2 . So I wrote it $(12-4)+2$ it's the same as $8+2$ produce $2^{\text {nd }}$ term.

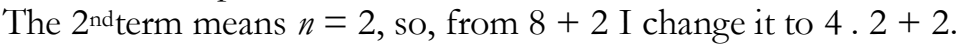

I continue to try to the $3^{\text {rd }}$ term, obtained $4.3+2=14$ it is correct.

I tried again to the $4^{\text {th }}$ term and obtained $4.4+2$ it is correct.

Then I write the $\mathrm{n}^{\text {th }}$ term formula is $4 n+2$.

$\mathrm{R} \quad$ : Have you ever gotten the number pattern material?

P1 : I did, but I forgot how.

From the result of work and interview with participant, obtained the first step is to form the $\mathrm{n}^{\text {th }}$ term formula by using the first term, the term in question is the fifth term, and using the difference, so the participant write the first formula is $U n=6 n-4$. Then this formula is used to determine the fifth term, by substituting $n=5$, then obtained $U_{5}=30-4=26$ (this result is not appropriate when the participant uses the difference to determine the $5^{\text {th }}$ term, so the participant replaces it with a new formula). In the second step, the participant tries to find a new formula by adding different (b), that is $a(n+b)-4$. Then the participant tries this formula to determine 
the second term, by substituting $n=2$, the result is obtained $U_{2}=36-4=32$ and tried for the fifth term, that is $U_{5}=54-4=50$ and this is wrong. Next, the participant changes the formula from $a(n+b)-4$ to $a(n-b)-4$, that is substitutes with subtraction. Then the participant proves this formula to determine the $6^{\text {th }}$ term, that is $U_{6}=12-4=8$. In the third step, the participant connects 8 with the $2^{\text {nd }}$ term. Because 8 is approaching the $2^{\text {nd }}$ term, the participant add 2 to become 10 . Then the participant writes $(12-4)+2=10$, and written back to be $8+2=4.2+$ 2. The participant tried to use the same pattern to determine the $3^{\text {rd }}$ and $4^{\text {th }}$ terms, that is $4.3+2$ $=14$ and $4.4+2=18$ it is correct. So the participant of writing the $\mathrm{n}^{\text {th }}$ term formula is $U_{n}=4 n$ +2 . The thought process of the first participantcan be seen in Figure 3.

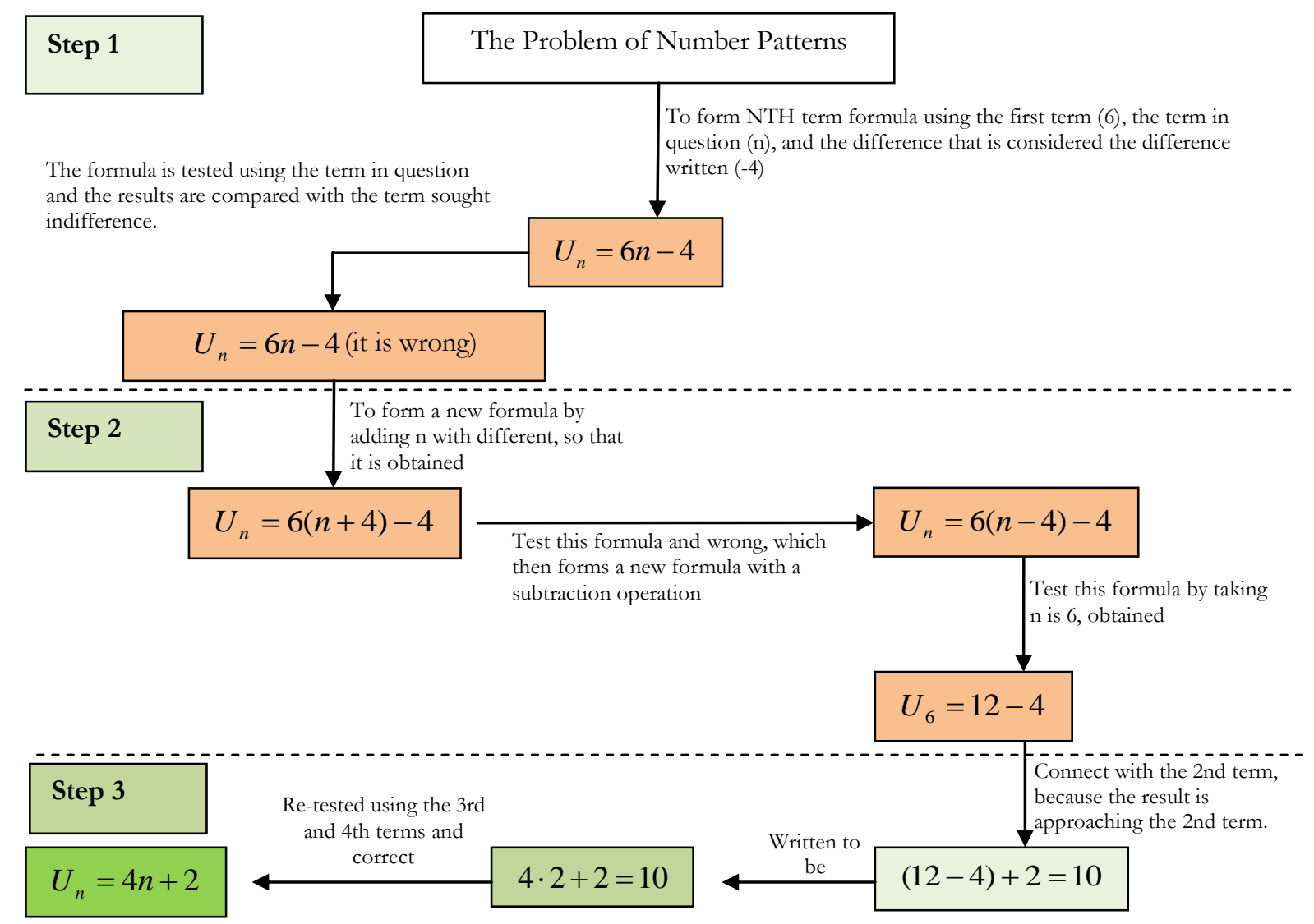

Figure 3. The Thinking Process Using Trial and Error Strategies by Lookingat Quantity Relationships

From Figure 3 we get a participant thinking process that uses a trial and error strategy by looking at the quantity relationship in generalizing a linear pattern consisting of three steps. The first step is called relating, namely, the participant connects between the first term, the term in question, and the difference. The participant makes the initial formula of the relationship between the first term, the term in question, and the difference to find the term in question, that is $U_{n}=a n-4$. Then the participant tests the initial formula that has been obtained to determine the term in question, which is $5^{\text {th }}$ term. The test results show that the initial formula obtained is wrong, and the participant directly changes the initial formula. The most important thought process in this first step is the participant's focus on numerics. The results of this study are consistent with the results of previous studies that students who focus on numerics will tend to use a trial and error strategy [7]. The results of other studies also showed that students based their 
decisions on only one test of the formula obtained [9]. Where the participant tests once the formula is obtained incorrectly, then the participant directly changes the wrong formula. The second step is called searching, where the participant tries to find similarities by changing the initial formula obtained using addition and subtraction operations to obtain the $\mathrm{n}^{\text {th }}$ term formula. Where the participant changes the initial formula to $U_{n}=a(n+4)-4$ and changed back to $a(n-$ 4) -4 . The thought process in this second step is that the participant remains focused on the initial formula and only modifies the formula by adding or subtracting with a difference. Then the participant re-tested the formula in the second step and found that the $\mathrm{n}^{\text {th }}$ term formula was still wrong. The third step is called extending, where the participant tries to find the $\mathrm{n}^{\text {th }}$ term formula by comparing the quantity obtained from the wrong formula with the quantity in the number pattern. The result is the participant managed to find a quantity relationship which is then used to generalize the linear pattern. This quantities relationship is important in generalizing. Where through quantity relations one can generalize easily [10],[11]. Previous research has shown that students who tend to focus on numerics and are not flexible to try other strategies and do not see the possible relationship between strategies, will tend to fail in generalizing [7]. The results of this study have shown something new, namely students who are trapped in a trial and error strategy and are then able to see the relationship of two quantities or can see the relationship between the two strategies of generalization; it will be able to generalize correctly.

\section{The Thinking Process of Trial and Error Strategy by Lookingat Patterns}

The thinking process using a trial and error strategy by looking at patterns is a thought process in generalizing patterns that start from a trial and error strategy and continued by looking at patterns that are formed, to generalize linear patterns correctly. The results of the work of the second participant using a trial and error strategy by looking patterns can be seen in Figure 4 . Next, the researcher (R) conducted an interview with the second participant (P2) to find out the participant's thought process in generalizing linear patterns using a trial and error strategy by looking at pattern below.

$\mathrm{R} \quad$ : Where did you get the formula $2^{2}+2$ and $3^{2}+1$ ?

P2 : I try to produce 6 , then for $3^{2}+1$ also I try to produce 10 .

$\mathrm{R} \quad$ : Why did you write down 2?

P2 : Try from a small number.

$\mathrm{R}$ : Why did you cross out $2^{2}+2$ and $3^{2}+1$ ?

P2 : Because the $\mathrm{n}^{\text {th }}$ term formula cannot be determined, so I crossed it out.

$\mathrm{R}$ : Where did you get it $2 \times 2+4,3 \times 2+4,5 \times 2+4,7 \times 2+4$,?

P2 : I tried again.

$\mathrm{R} \quad$ : It has nothing to do with what was written before $2^{2}+2$ ?

P2 : Not

$\mathrm{R} \quad$ : How about the $5^{\text {th }}$ term?

P2 : This means the $5^{\text {th }}$ term is $8 \times 2+4=20$. So it is not by following the 5 th term, so I will not continue.

R : Where did you get it $n \times 4+2$.

P2 : I was writing for the first term is $2 \times 1+4$, then I return with 4 in front, so that $4+2$. Then I proceed to the second term, that is $2 \times 4+2$ in to produce 10 , and I try again for the $3 \mathrm{rd}$ term, that is $3 \times 4+2$ also produces 14 . So I wrote the general form is $U_{n}=n \times 4+2$. 


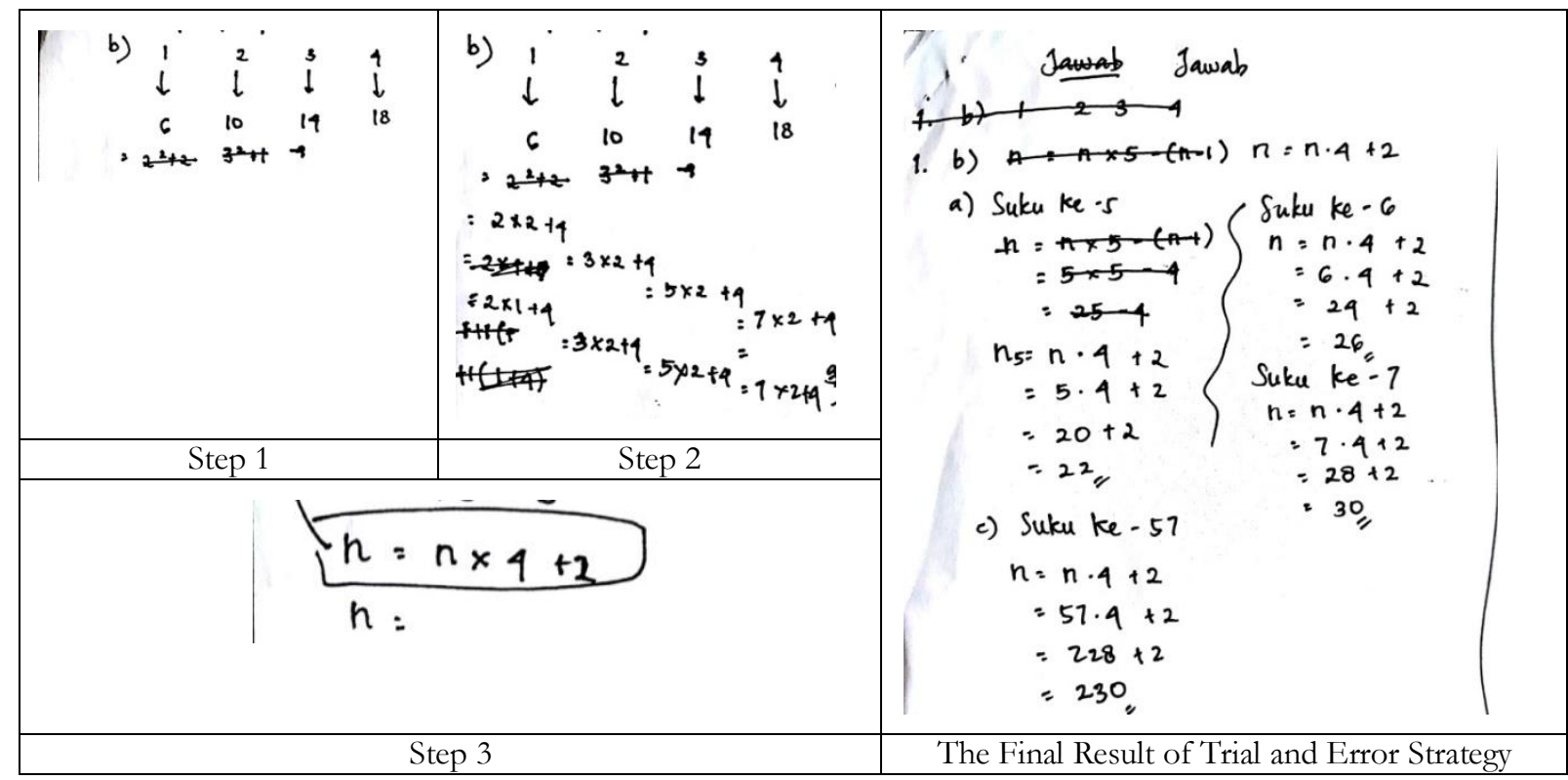

Figure 4. Work Results of Second Participant Using Trial and Error Strategy

From Figure 4 and the interview, excerpts obtained the participant thought process in generalizing linear patterns using a trial and error strategy by looking at pattern consisting of three steps. The first step is participant try to determine first term with small number is 2 and doing calculations in order to get the results is 6 , namely by using $2^{2}+2$ which yields 6 . Then the participant tries to find a formula for the second term, that is $3^{2}+1$ which yields 10 . But the participant could not find the $\mathrm{n}^{\text {th }}$ term formula, so it was crossed out by the participant. Then, the participant proceeds to the second step, which is trying to find a formula again by writing a new formula, that is $2 \times 2+4$ for the first term. But the participant also cannot generalize this new formula. Then, the participant proceeds to thethird step, where the participant tries to form a new $\mathrm{n}^{\text {th }}$ term formula by reversing the formula $2 \times 2+4$ becomes $4+2$. The participant tries to find the $2^{\text {nd }}$ term, that is $2 \times 4+2=10$, and try again for the $3^{\text {rd }}$ term, that is $3 \times 4+2=14$. So by looking at the similarity of the last formula,the participant generalizes linear patterns, that is $n \times 4+2$. The thinking process of the second participant that also uses a trial and error strategy by looking at patterns in generalizing linear patterns can be seen in Figure 5. 
Numerical: Jurnal Matematika dan Pendidikan Matematika, 4(1), Juni 2020, 1-12

Yayan Eryk Setiawan

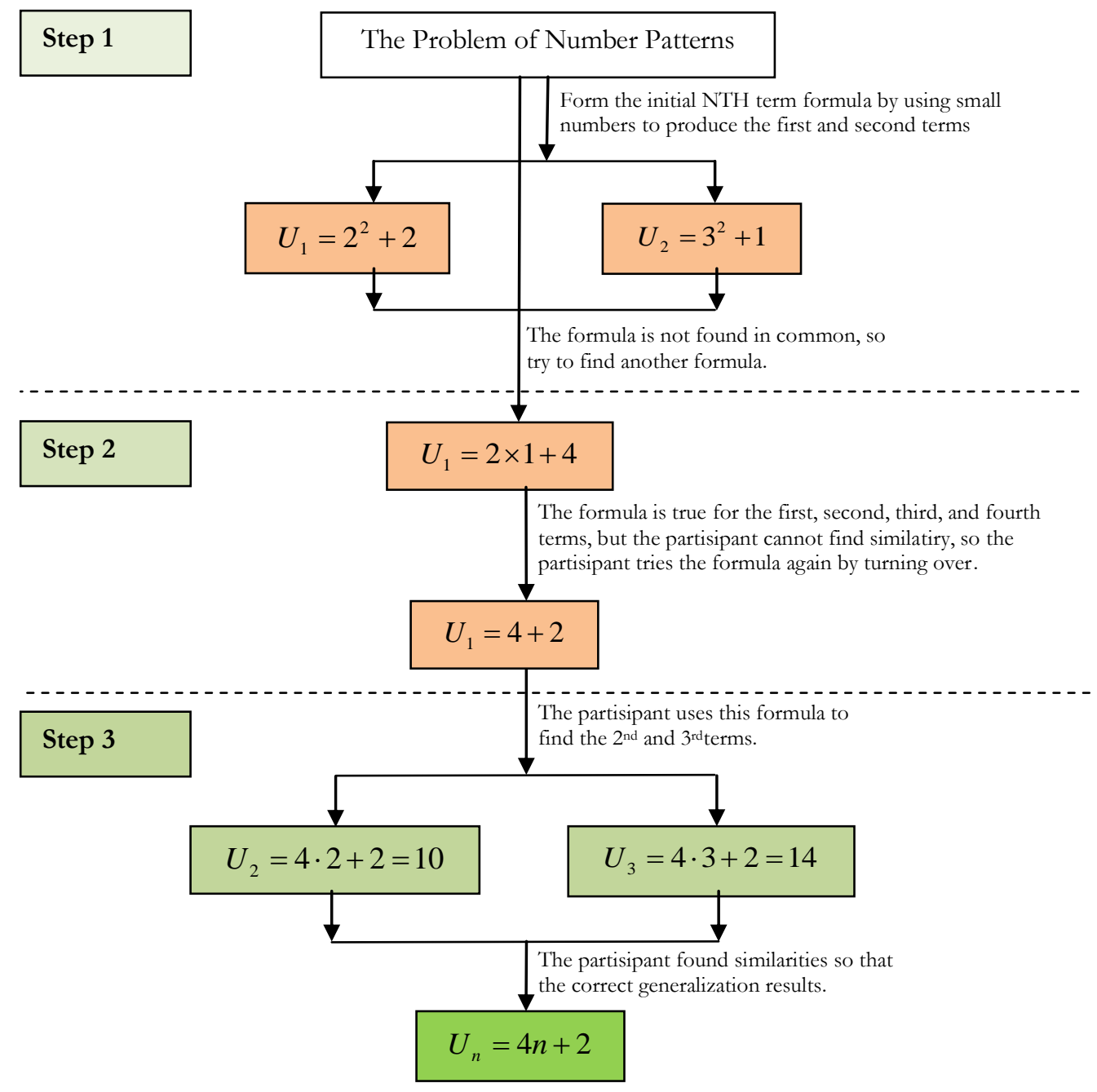

Figure 5. The Process of Thinking Using Trial and Error Strategy by Lookingat Patterns

From Figure 5, the participant's thought process consists of three steps. The first step is called relating, that is, the participant connects small positive integers by using arithmetic operations to obtain the first term and the second term. The participant did not see any difference, where the participant focused on forming the formula to determine the first term. Because the formula for obtaining the first term is different from the formula for obtaining the second term, the participant does not use the initial formula that has been obtained. The thought process in this first step is the participant focus on numerics and focus on a portion of number patterns, that is the participant only focuses on the first term and the second term. The results of previous studies indicate that students who focus on the first term and the second term will experience failure in generalizing patterns, due to being trapped in a recursive strategy [12][13][2]. Other research results also show that students who only focus on a part of a number pattern (selective processing) will fail to generalize the pattern[14]. The results of this study indicate that students who focus on the first and second terms (selective processing) will be trapped in a trial and error strategy. Then the second step is called searching, where the participant reformulates the first term, second term, and third term to find similarities between terms in a number pattern. The thought process in this second step is that the participant remains focused on forming a new formula for the first, second, and third terms, without modifying the formula obtained previously. Furthermore the participant still could not find any similarity from the new 
formula for the first, second, and third terms. In the third step is called extending, the participant is trying to find patterns that apply to the first term, second term, and third term to obtain the $\mathrm{n}^{\text {th }}$ term. Finally the participant managed to find a pattern that applies to the $\mathrm{n}^{\text {th }}$ term. The results of this study are also consistent with previous research showing that students who tend to focus on numerics and do not see the possible relationship between strategies, will tend to fail in generalizing[7]. The results of this study have shown something new, namely students who are trapped in trial and error strategies and are then able to see patterns from formulas that were made before; they will be able to generalize correctly.

From the two thought processes that use a trial and error strategy in generalizing linear patterns, a comparison of thought processes using a trial and error strategy by looking at quantities relationship and by looking at patterns that can be seen in Table 1.

Table 1. Comparison of Thinking Processes from Trial and Error Strategies that Looking at Quantities Relationship with Looking at Patterns.

\begin{tabular}{cll}
\hline Steps & \multicolumn{1}{c}{ Looking at Quantities Relationship } & \multicolumn{1}{c}{ Looking at Patterns } \\
\hline Step 1 & $\begin{array}{l}\text { Form the initial } \mathrm{n}^{\text {th }} \text { term formula by using the } \\
\text { first term, the term in question, and the } \\
\text { difference to look for the term in question. }\end{array}$ & $\begin{array}{l}\text { Form the initial } \mathrm{n}^{\text {th }} \text { term formula by } \\
\text { get the first term and the second term. }\end{array}$ \\
Step 2 & $\begin{array}{l}\text { Change the initial } \mathrm{n}^{\text {th }} \text { term formula by using } \\
\text { addition and subtraction operations while } \\
\text { focusing on the difference and initial formula. }\end{array}$ & $\begin{array}{l}\text { Form a new } \mathrm{n}^{\text {th }} \text { term formula for the } \\
\text { by removing the initial } \mathrm{n}^{\text {th }} \text { term formula. }\end{array}$ \\
Step 3 & $\begin{array}{l}\text { Compares the quantity obtained from the } \\
\text { formula in the second step with the quantity in } \\
\text { the number pattern, so that the correct } \mathrm{n}^{\text {th }} \\
\text { term formula is obtained. }\end{array}$ & correct $\mathrm{n}^{\text {th }}$ term formula. and third terms, so got the \\
&
\end{tabular}

From Table 1 it is known that the most important finding of this study is the trial and error strategy can be used as a generalization strategy if the trial and error strategy is followed by a quantity relationship strategy and a pattern-finding strategy. In addition, the factors causing the emergence of a trial and error strategy are generalization processes that focus on numerics and focus on selective processing, which only focus on the first and second terms, and only focus on the terms in question. The reason for the emergence of a trial and error strategy is also because students forget about the formula for determining the $\mathrm{n}^{\text {th }}$ term. This means that learning linear patterns should emphasize the concept of linear patterns that do not only emphasize memorization. Because understanding concepts have an important role in learning mathematics [15],[16]. It is also important to equip students with basic knowledge in solving mathematical problems [17]-[21].

\section{CONCLUSIONS}

Although this research is limited to only two participants, the results of this study contribute to the discovery of new things, namely that the trial and error strategy can be used as a linear pattern generalization strategy if it is related to the quantity relationship strategy and the pattern-finding strategy. Future studies can examine other trial and error strategies that can be used to generalize linear patterns, or examine trial end error strategies from quadratic, exponential, or cubic patterns. 


\section{REFERENCES}

[1] Kemendikbud, Peraturan Menteri Pendidikan dan Kebudayaan Republik Indonesia Nomor 24 Tahun 2016 Tentang Kompetensi Inti dan Kompetensi Dasar Pelajaran Pada Kurikulum 2013 Pada Pendidikan Dasar dan Pendidikan Menengah. Indonesia, 2016.

[2] Y. E. Setiawan, Purwanto, I. N. Parta, and Sisworo, "Generalization Strategy of Linear Patterns From Field-Dependent Cognitive Style," Journal on Mathematics Education, vol. 11, no. 1, pp. 77-94, 2020, doi: http://doi.org/10.22342/jme.11.1.9134.

[3] Y. E. Setiawan, Pembelajaran Pola Bilangan. Lumajang: CV. Al-Mukmin Yes, 2019.

[4] K. Çiğdem, "Analyzing Middle School Students' Figural Pattern Generating Strategies Considering A Quadratic Number Pattern," Abant İzet Baysal Üniversitesi Eğitim Fakültesi Dergisi, vol. 17, no. 1, pp. 250-267, 2017.

[5] J. Jureczko, "The strategies of using a special kind of number patterns in different stages of education," Educational Research and Reviews, vol. 12, no. 12, pp. 643-652, 2017, http://doi.10.5897/ERR2017.3244.

[6] P. Liljedahl, "Repeating Pattern or Number Pattern: the Distinction is Blurred," Focus on Learning Problems in Mathematics, vol. 26, no. 3, pp. 24-42, 2004.

[7] J. R. Becker and F. Rivera, "Generalization Strategies of Beginning High School Algebra Students," in Proceedings of the 29th Conference of the International Group for the Psychology of Mathematics Education, 2005, vol. 4, pp. 121-128.

[8] A. B. Ellis, "A Taxonomy for Categorizing Generalizations: Generalizing Actions and Reflection Generalizations," Journal of the Learning Sciences, vol. 16, no. 2, pp. 37-41, 2007, doi: http://doi.org/10.1080/10508400701193705.

[9] J. Bishop, "Linear Geometric Number Patterns: Middle School Students' Strategies," Mathematics Education Research Journal, vol. 12, no. 2, pp. 107-126, 2000.

[10] A. B. Ellis, "The Influence of Reasoning with Emergent Quantities on Students' Generalizations," Cognition and Instruction, vol. 25, no. 4, pp. 439-478, 2007.

[11] A. B. Ellis, "Algebra in the Middle School : Developing Functional Relationships Through Quantitative Reasoning," in Early Algebraization, Advances in Mathematics Education, E. Knuth, J. Cai, Ed. USA: Springer-Verlag Berlin Heidelberg, 2011, pp. 215-216.

[12] B. L. Chua, "Features of Generalising Tasks Help or Hardle to Expressing Generality?," Amt, vol. 65, no. 2, pp. 18-24, 2009.

[13] M. Hourigan and A. Leavy, "Geometric Growing Patterns What's the rule ?," $A P M C$, vol. 20, no. 4, pp. 31-40, 2015.

[14] F. Rivera, "The Distributed Nature of Pattern Generalization," $P N A$, vol. 9, no. 3, pp. 165-191, 2015.

[15] Y. E. Setiawan and Mustangin, "Validitas Model Pembelajaran IDEA (Issue, Discussion, Establish, and Apply) untuk Meningkatkan Pemahaman Konsep," Jurnal Penelitian Pendidikan dan Pengajaran Matematika, vol. 6, no. 1, pp. 53-60, 2020.

[16] Y. E. Setiawan, "Analisis Kesalahan Siswa dalam Menilai Kebenaran Suatu Pernyataan," Jurnal Didaktik Matematika, vol. 7, no. 1, pp. 13-31, 2020, doi: http://doi.org/10.24815/jdm.v7i1.14495. 
[17] Y. E. Setiawan, "Analisis Kemampuan Siswa dalam Pembuktian Kesebangunan Dua Segitiga," Al-Khwarizmi: Jumal Pendidikan Matematika dan Ilmu Pengetahuan Alam, vol. 8, no. 1, pp. 23-38, 2020, doi: http://doi.org/10.24256/jpmipa.v8i1.800.

[18] M. S. Anwar, C. Choirudin, E. F. Ningsih, T. Dewi, and A. Maseleno, "Developing an Interactive Mathematics Multimedia Learning Based on Ispring Presenter in Increasing Students' Interest in Learning Mathematics," Al-Jabar: Jurnal Pendidikan Matematika, vol. 10, no. 1, pp. 135-150, Jul. 2019, doi: http://doi.org/10.24042/ajpm.v10i1.4445.

[19] Choirudin, Eka Fitria Ningsih, M. Saidun Anwar, Intan Ratna Sari, and Suci Amalia, "Pengembangan Perangkat Pembelajaran Etnomatematika Pada Situs Purbakala Pugung Raharjo," Pi: Mathematics Education Journal, vol. 3, no. 1, pp. 18-27, 2020, doi: http://doi.org/10.21067/pmej.v3i1.3755.

[20] Apri Wahyudi and Choirudin, "Pengembangan Alat Peraga Pembelajaran Matematika Materi Perkalian Berbasis Montessori," Jurnal Manajemen Pendidikan Islam Al-Idarah, vol. 4, no. 2, pp. 33-39, 2019.

[21] S. Subandi, C. Choirudin, M. Mahmudi, N. Nizaruddin, and H. Hermanita, "Building Interactive Communication with Google Classroom," International Journal of Engineering \& Technology, vol. 7, no. 2. 13, pp. 460-463, Apr. 2018, doi: http://doi.org/10.14419/ijet.v7i2.13.18141. 
Numerical: Jurnal Matematika dan Pendidikan Matematika, 4(1), Juni 2020, 1-12

Yayan Eryk Setiawan 